\title{
Low-level Determination of Residual Methyl Methane Sulfonate and Ethyl Methane Sulfonate in Pharmaceuticals by Gas Chromatography with Mass Spectrometry
}

\author{
M.SARAT, M.RAMAKRISHNA, Y.SURESH, S.HARIKRISHNA*, \\ C.RAMBABU, K.KISHORE and K.NAGABHUSHANA REDDY
}

\author{
Analytical Development, \\ Matrix Laboratories Ltd, Hyderabad-500055, India. \\ harikrishnasontineni@yahoo.co.in
}

Received 8 August 2009; Accepted 2 October 2009

\begin{abstract}
A capillary gas chromatographic method using mass spectrometric detection was developed and validated for the trace analysis (ppm level) of methyl methane sulfonate and ethyl methane sulfonate in pharmaceutical drug substances. The method utilizes a capillary column (DB-624) with 6\% cyanopropyl phenyl and 94\% dimethyl polysiloxane stationary phase. A dissolve-and-injection approach was adopted for sample introduction in a split less mode. Mixture of (80:20) ratio of methanol and chloroform was used as a diluent or sample solvent. A limit of detection of about $0.17 \mu \mathrm{g} / \mathrm{g}(0.17 \mathrm{ppm})$ for methyl methane sulfonate and $0.18 \mu \mathrm{g} / \mathrm{g}(0.18 \mathrm{ppm})$ for ethyl methane sulfonate were achieved and limit of quantitation of $0.52 \mu \mathrm{g} / \mathrm{g}(0.52 \mathrm{ppm})$ for methyl methane sulfonate and $0.54 \mu \mathrm{g} / \mathrm{g}(0.54 \mathrm{ppm})$ for ethyl methane sulfonate were achieved for alkyl sulfonates in drug substance samples.
\end{abstract}

Keywords: Pharmaceutical analysis, Alkyl methyl sulfonates, Low-level determination.

\section{Introduction}

Recently the potential health hazards of trace amounts of mesylate esters, including methyl methane sulfonate (MMS) and ethyl methane sulfonate (EMS), in pharmaceuticals have attracted the attention of regulatory authorities. These mesylate esters are known to be potent mutagenic, carcinogenic and teratogenic compounds ${ }^{1-4}$. There presence in the 
pharmaceutical products may be the results of leftover starting materials, or formed as byproducts between methanesulfonic acid (often used as a counterion) and alcohols often uses as a manufacturing process. Although official guidelines have not been established the concentration of these compounds are expected to be controlled at a level of less than or equal to $1.0 \mu \mathrm{g} / \mathrm{g}$. Therefore, it is of great importance to develop analytical methods that are sensitive enough and meet all the regulatory requirements.

The pure mesylate esters are liquids at ambient temperature with a boiling point around $200{ }^{\circ} \mathrm{C}$. Therefore, it is feasible to separate and quantify these compounds by gas chromatography mass spectrometry (GC-MS). Ramjit et al. ${ }^{5}$ reported a method using capillary gas chromatography in combination with mass spectrometry (MS) for the determination of MMS and EMS in pharmaceuticals. A different approach was adopted by the other researchers ${ }^{6-8}$ using headspace GC after mesylate esters were converted in to thiocyanate esters through derivatisation. MS detection was also used for headspace analysis ${ }^{9}$. The analysis of mesylate esters using HPLC is not straightforward because of the specific chemical and physical properties of these compounds.

This short communication describes a simple and sensitive method for the determination of MMS and EMS in pharmaceuticals using capillary GC with mass spectrometry (MS) in selective ion monitoring mode (SIM) or selective ion recording (SIM) mode. The limit of detection and limit of quantitation were determined to be $0.17 \mathrm{ppm}$ and $0.18 \mathrm{ppm}$ and limit of quantitation were determined to be $0.52 \mathrm{ppm}$ and $0.54 \mathrm{ppm}$ with respect to $600 \mathrm{mg} / \mathrm{mL}$ of API, respectively. The method utilizes a dissolve and injects approach for sample preparation and introduction. The samples were injected in the splitless mode and quantitation was achieved using a single point external standard calibration. The current research work deals with the determination of Alkali sulfates in the drug substance. The work also includes the partial validation and method development.

\section{Experimental}

A Perkin Elmer Clarus 500 model equipped with mass detector and autosampler was used in the experiment. Data acquisition and processing were conducted using the Turbo mass software on a Pentium computer (Digital equipment Co).

\section{Chemicals}

MMS and EMS were purchased from Fluka chemicals. LC grade methanol was purchased from Merch chemicals (Merck chemicals, Mumbai, India) and chloroform of A.R grade was purchased from Rankem (RANKEM, New Delhi, India). Samples of Ritonavir are received from the process Research department of Matrix laboratories Ltd, India.

\section{Preparation of solutions}

The stock solutions of mesylate esters were prepared by dissolving $10.3 \mathrm{mg}$ and $10.8 \mathrm{mg}$ each (Individually in separate $100 \mathrm{~mL}$ volumetric flasks) of the compounds in sample solvent, which includes the mixture of (80:20) ratio of methanol and chloroform. The diluted stock solution was prepared by pippetting each $1 \mathrm{~mL}$ of the stock solution in to a $100 \mathrm{~mL}$ volumetric flask and diluting to volume with the sample solvent. The working standard solutions $(0.52 \mathrm{ppm}$ and $0.54 \mathrm{ppm}$ ) was prepared by further diluting $3.0 \mathrm{~mL}$ of the diluted stock solution in to $10 \mathrm{~mL}$ volumetric flask. The sample solution was prepared by accurately weighing about $600 \mathrm{mg}$ of the drug substance in to a $20.0 \mathrm{~mL} \mathrm{GC}$ vial and adding $1.0 \mathrm{~mL}$ of the sample solvent. 


\section{Operating conditions}

The GC separation was conducted on a J\&W Scientific DB-624 column with a dimension of $30 \mathrm{~m} \times 0.53 \mathrm{~mm}$ and a film thickness of $3 \mathrm{um}$.Helium was used as a carrier gas at a constant pressure of 20.0 Psi. The GC oven temperature programme was isothermal at $110{ }^{\circ} \mathrm{C}$ constant throughout the run. The injector temperature was set at $140{ }^{\circ} \mathrm{C}$. The $\mathrm{GC}$ runtime was 20 minutes.

The samples were injected with the Perkin Elmer autosampler. The inlet temperature was kept at $140{ }^{\circ} \mathrm{C}$. A glass splitless injection liner with quartz wool was obtained from Perkin Elmer, (USA). The samples were injected in a splitless mode with a $1.0 \mu \mathrm{L}$ injection volume unless otherwise specified.

A selective ion monitoring (SIM) or selective ion-recording (SIR) mode was used as MS method for quantification of alkyl mesylates in drug substances. The fragment ion at $\mathrm{m} / \mathrm{z}$ 79 was used as SIR for both methyl methane sulfonate and ethyl methane sulfonate.

\section{Results and Discussion}

\section{Method development and optimization}

The challenge was to achieve the desired detection and qauntitation at very low level using the instrument, i.e. gas chromatograph with mass spectrometrometer (GC-MS). To obtain good separation and the desired sensitivity, one approach is to select either most prominent fragment ion as selective ion recording mode (SIR) in MS and if require increase the sample amount injected in to the GC-MS system. To decrease the interference of other substances with the alkyl sulphonates, other fragments also can be selected as selective ion recording (SIR) mode. The adoption of mega bore capillary column $(0.53 \mathrm{~mm}$ I.D) with a high capacity bonded stationary phase seems to be the obvious choice. Relatively high flow rate of carrier gas (20.0 Psi pressure) and suitable isothermal column temperature in combination with a moderate inlet temperature $\left(140{ }^{\circ} \mathrm{C}\right)$ may allow a large injection volume without significant deterioration in column efficiency.

The effect of concentration on separation and quantitation of the mesylate esters was investigated by injecting $1.0 \mu \mathrm{L}$ of the stock solution $(180 \mathrm{ppm})$ and working standard solutions of $0.52 \mathrm{ppm}$ and $0.54 \mathrm{ppm}$ respectively. Further studies were not done to determine the maximum injection. An injection volume of $1 \mu \mathrm{L}$ was chosen for this method.

The effect of isothermal column temperature on the separation of the mesylate esters was investigated. An aliquot of $1.0 \mu \mathrm{L}$ of the sample was injected in the splitless mode. The results show that the peak shape and peak width were not affected by the isothermal column temperature. The isothermal column temperature $110{ }^{0} \mathrm{C}$ was chosen, which allowed baseline separation of the two-mesylate esters from each other from interfering peaks in the sample solvent.

This method utilizes a dissolve-and-inject approach for the residual mesylate esters analysis. Several factors were considered in selection of a sample solvent, including the purity, its ability to dissolve the analyte, and its chemical compatibility with compounds of interest. To detect the mesylate esters at about $0.5 \mu \mathrm{g} / \mathrm{g}$ level, the purity of sample solvent is critical. It has been observed in our laboratory that the HPLC grade solvents are generally suitable. Because when we inject a blank we will not get any interference in blank. In each case $1.0 \mu \mathrm{L}$ of the solvent was injected. The tested sample concentration of drug substances was $600 \mathrm{mg} / \mathrm{mL}$. Because the mesylate esters have relatively high boiling point. The mesylate esters showed reasonable ability in the diluent (80:20) ratio of methanol and 
chloroform mixture. Using this diluent the two alkyl sulfonates were very well separated in this method. This is important because many pharmaceuticals are in salt forms, which sometimes show limited solubility in pure organic solvents.

\section{Method validation}

The validation work was conducted according to the ICH (International Conference on Harmonization) guidelines ${ }^{10-13}$. The validated method parameters include specificity, limit of detection, limit of quantitaion, precision, linearity and accuracy.

The detection limit (LOD) of the method for the mesylate esters was estimated from a total ion chromatogram of a solution containing about $0.17 \mathrm{ppm}$ for methyl methane sulfonate and $0.18 \mathrm{ppm}$ for ethyl methane sulfonate Figure 1. From the total ion chromatogram a signal to noice ratio of 3.58 and 3.01 was obtained for MMS and EMS, respectively. A second instrument (Same instrument manufacturer) was used to repeat the experiment and similar results were obtained. All two peaks have a signal to noice ratio of near about 3 , indicating that this method is capable of detecting about $0.5 \mathrm{ppm}$ level of the esters in the drug substance, which is equalent to about $1.0 \mu \mathrm{g}$ each of the mesylate esters per $0.6 \mathrm{~g}$ of API $(0.5 \mathrm{ppm})$.

\section{LOD Total ion chromatogram of MMS \& EMS}

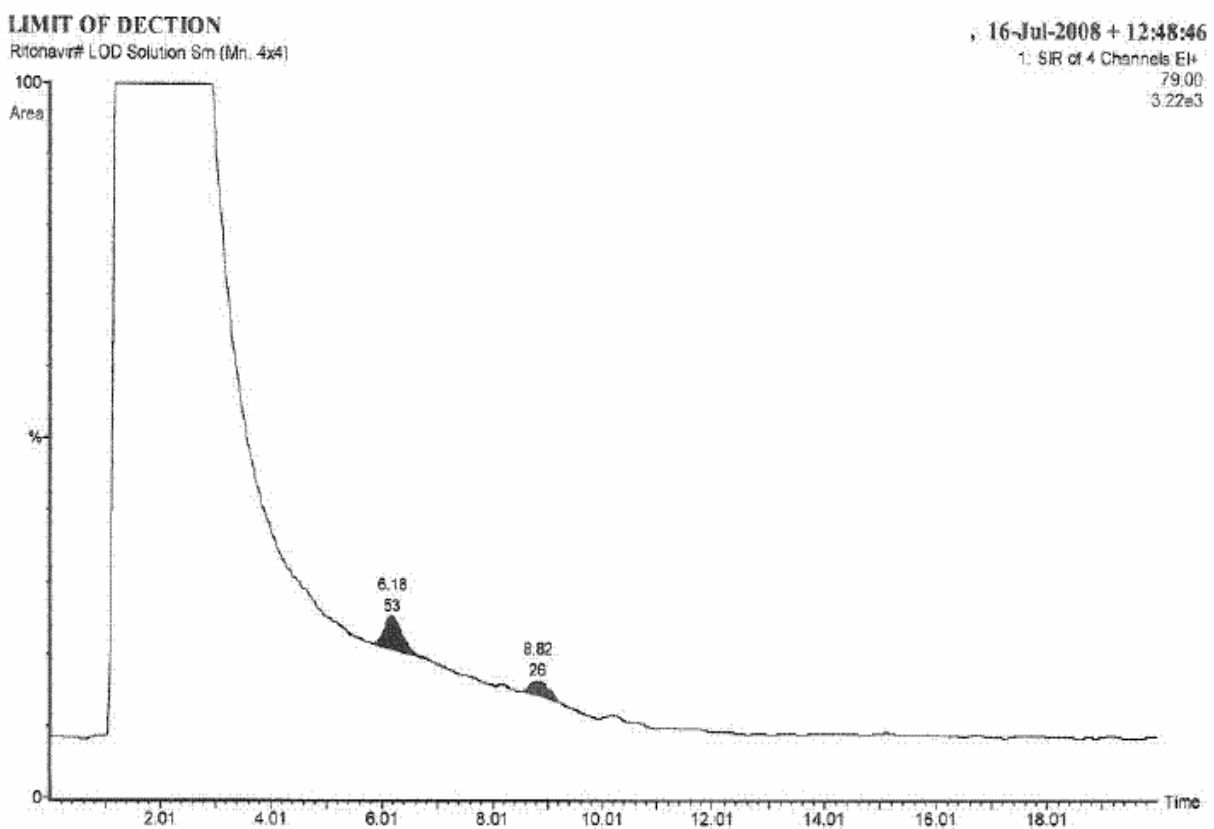

Figure 1. LOD total ion chromatogram of MMS \& EMS.

In the pharmaceutical industry, the quantitation limit (LOQ) was defined as the lowest amount of analyte in a sample that can be quantitatively determined with suitable precision and accuracy. The LOQ was determined to be less than or equal to $0.52 \mu \mathrm{g} / \mathrm{g}(0.52 \mathrm{ppm})$ and $0.54 \mu \mathrm{g} / \mathrm{g}(0.54 \mathrm{ppm})$ for MMS and EMS, based on the precision and accuracy data discussed below. LOQ chromatogram shown in Figure 2. 
LOQ Total ion chromatogram of MMS \& EMS

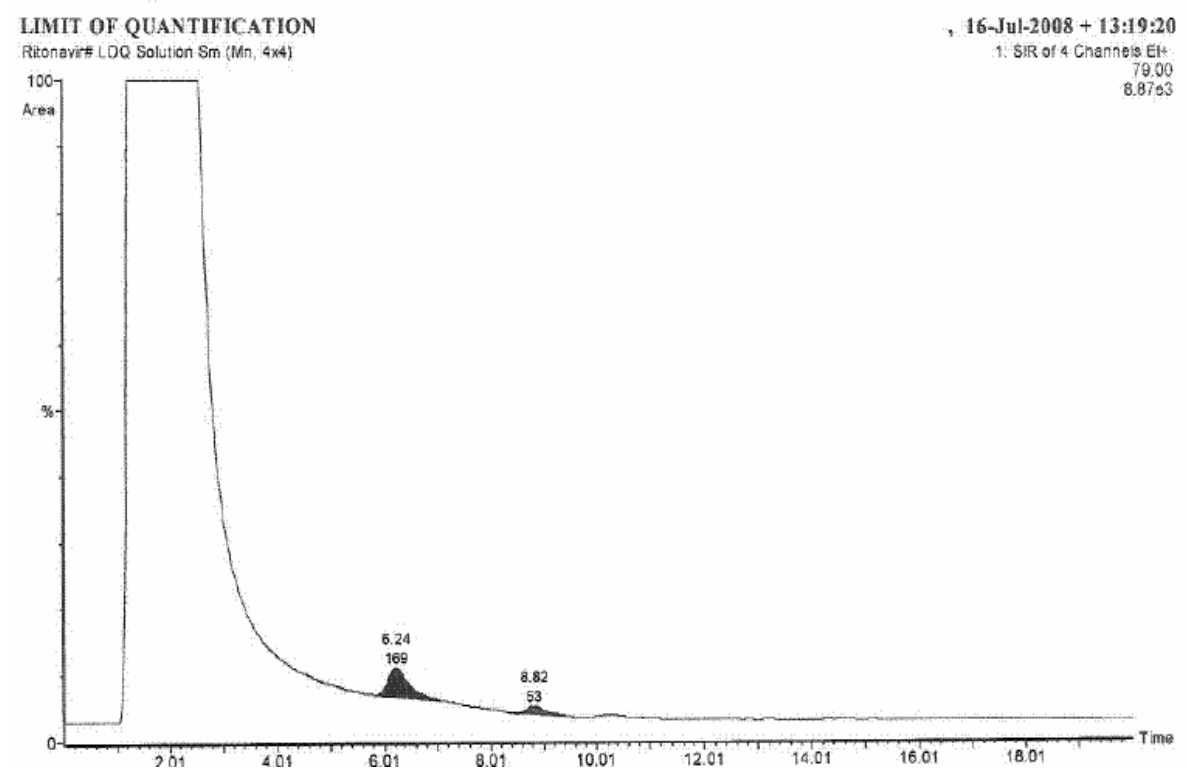

Figure 2. LOQ total ion chromatogram of MMS \& EMS

Linearity of the method was determined by preparing and analyzing a series of 5 standard solutions to cover the concentration range of LOQ to $1.50 \mathrm{ppm}$ each for mesylate esters. Regression analysis of the peak area versus concentration data yield an R2 $>0.99$ for each of the two calibration curves. Linearity chromatogram shown in Figure 3.

Linearity Total ion chromatogram of MMS \& EMS

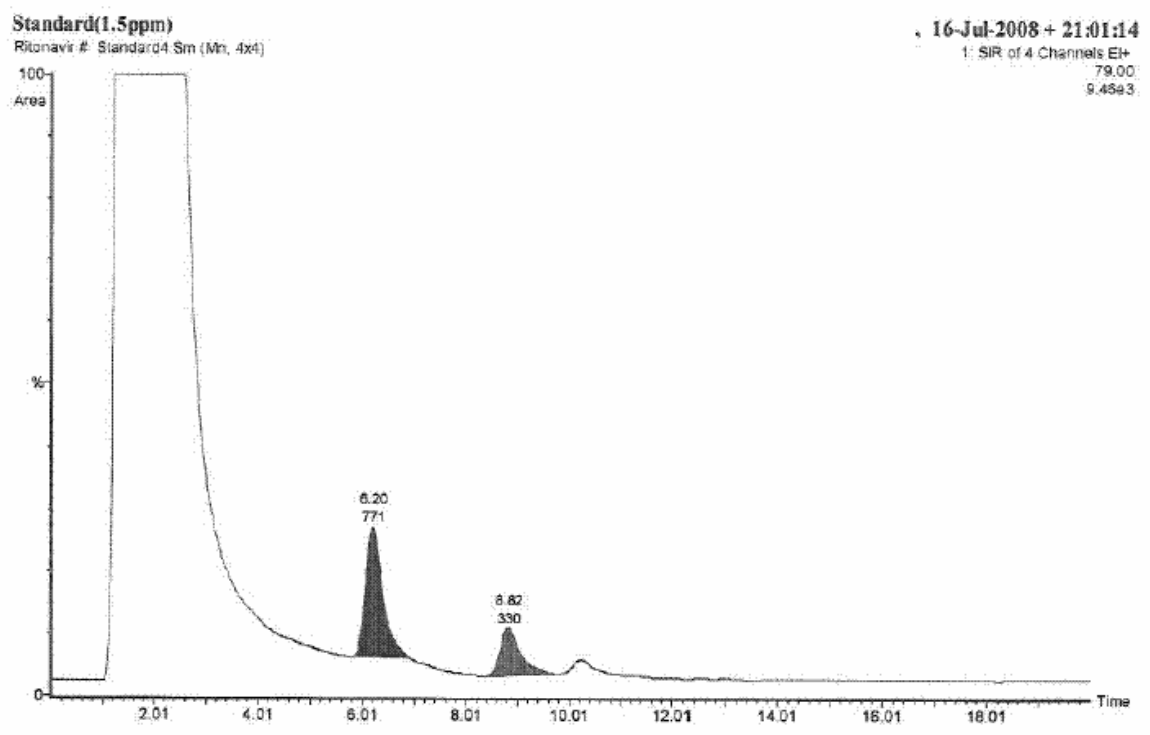

Figure 3. Linearity total ion chromatogram of MMS \& EMS. 
The experimental results also shown that, this method have excellent precision without using an internal standard. Multiple injections were made for the standard solutions containing $0.52 \mathrm{ppm}$ and $0.54 \mathrm{ppm}$ each of the mesylate esters. For six injections of the standard solutions, the R.S.D of the peak area was in the range of $93.3 \%$ and $90.9 \%$ respectively.

Accuracy of the method was determined by analyzing a drug substance samples spiked with known amount of the mesylate esters. The spiked levels (Figure 4) were 0.52 and 0.54 ppm. The recovery was in the range of $93.3 \%$ and $90.9 \%$, respectively. Because this method uses the dissolve-and-inject approach, for every sample injection, about $600 \mathrm{mg}$ of the drug substance is introduced in the injection port. The accumulation of drug substance may have negative effect on the recovery. Therefore the injection liner should be replaced after every sequence of 10-15 injections.

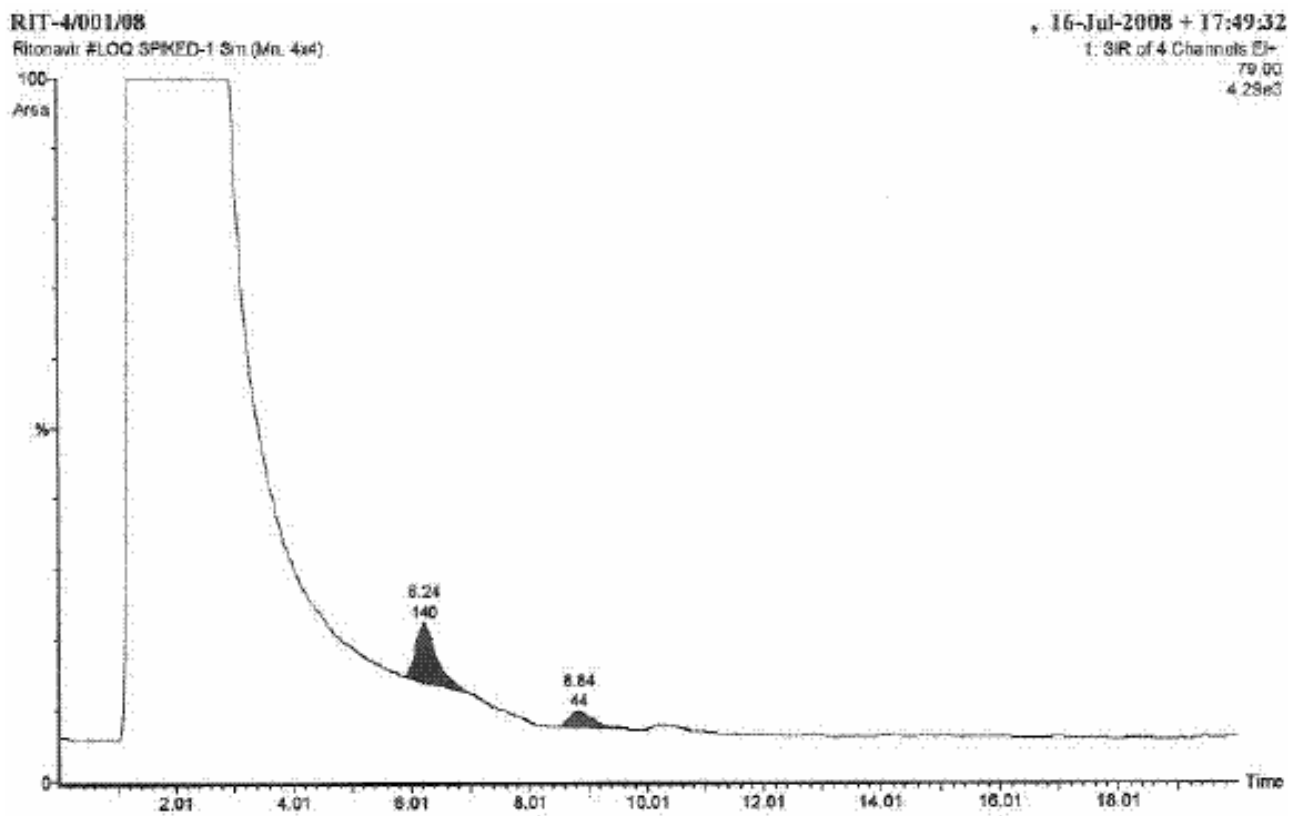

Figure 4. Accuracy total ion chromatogram of MMS \& EMS.

\section{Conclusion}

A simple and sensitive GC-MS method had been developed and validated for the trace analysis of mesylate esters in pharmaceuticals. The validation has been conducted according to ICH guidelines, compared with the previously reported methodologies; this method utilizes a gas chromatograph mass spectrometer, which is available in the pharmaceutical industry. This method is sensitive enough to detect $0.5 \mathrm{ug} / \mathrm{g}$ and quantify $0.5 \mathrm{ug} / \mathrm{g}$ level of the mesylate esters in pharmaceutical products.

\section{Acknowledgment}

The authors wish to thank the management of Matrix Laboratories Ltd. For supporting this work. Authors wish to acknowledge the Process Research Department for providing the samples for this research. We also would like to thank colleagues from the separation science division of Analytical Development for their co-operation in carrying out this work. 


\section{References}

1. Ehling U H, Cumming R B and Malling H V, Mutation Res., 1968, 5, 417.

2. Petzold G L and Swenberg J A, Cancer Res., 1978, 38, 1589.

3. Synder R D and Regan J D, Mutation Res., 1981, 91, 307.

4. Sega G A, Sluder A E, McCoy L S, Owens J G and Generoso E E, Mutation Res., 1986, 159, 55.

5. Ramjit H G, Singh M M and Codington A B, J Mass spectrom., 1996, 31, 867.

6. Colli G, Mauleon D and Vessman J, Pharmeuropa, 2000, 12, 401.

7. Leigh P and Bowker M, Pharmaeruopa, 2000, 12, 734

8. Lee C R, Guivarch F, Vandau C N, Taessier D and Krstulovic A M, Int J Pharm., 2000, 195, 159.

9. Lee C R, Guivarch F, Vandau C N, Taessier D and Krstulovic A M, Analyst, 2003, 128, 857.

10. ICH Q2A: Text on validation of analytical procedures: terms and definitions, In: International Conference on Harmonization, Fed, Reg. (60 FR 11260), 1 March 1995.

11. ICH Q2B: Text on validation of analytical procedures: methodology, In: International Conference on Harmonization, Fed, Reg. (62 FR 27463), 19 May 1997.

12. ICH Q3A: Impurities in new drug substances, In: International Conference on Harmonization, Fed, Reg. (68 FR 6924), 11 February 2003.

13. ICH Q3B: Impurities in new drug products, In: International Conference on Harmonization, Fed, Reg. (62 FR 27454), 19 May 1997. 


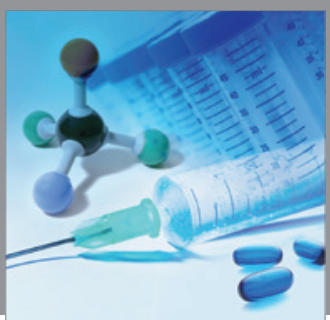

International Journal of

Medicinal Chemistry

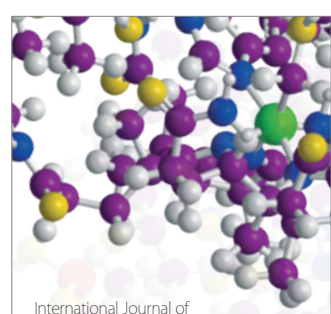

Carbohydrate Chemistry

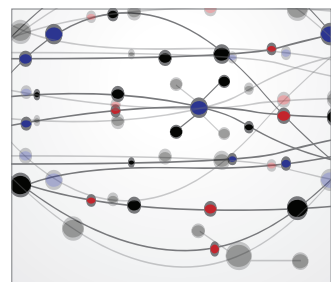

The Scientific World Journal
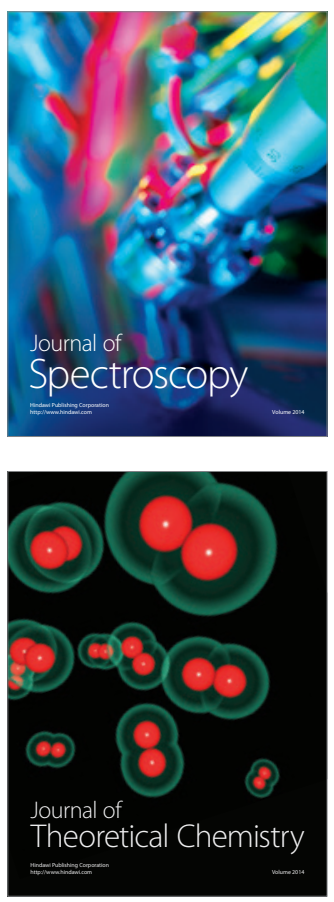
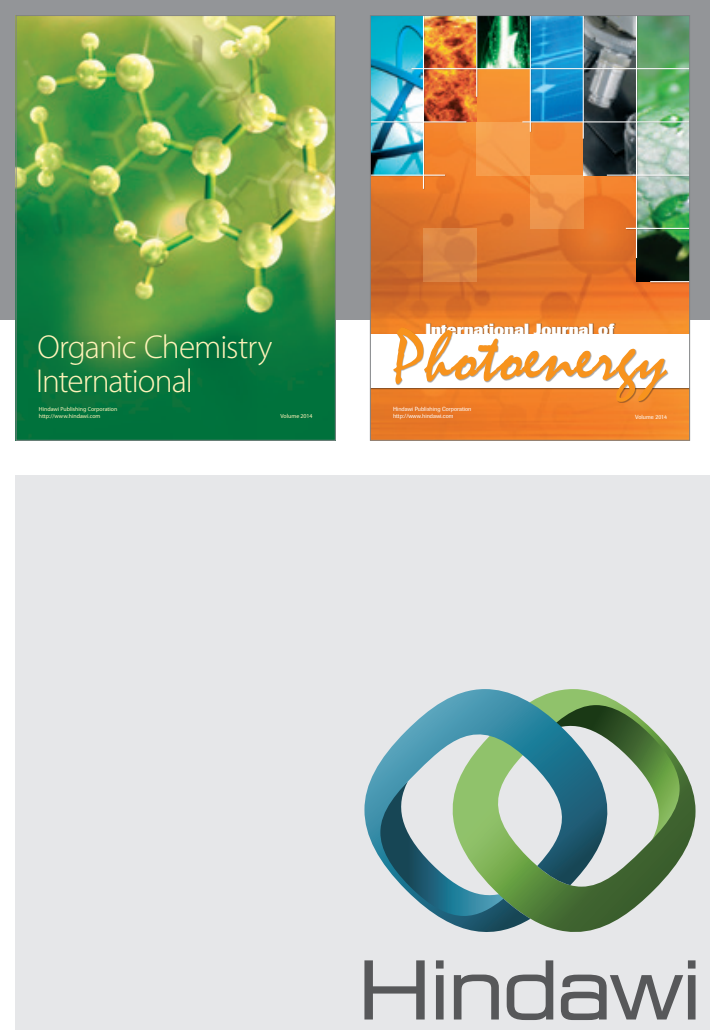

Submit your manuscripts at

http://www.hindawi.com
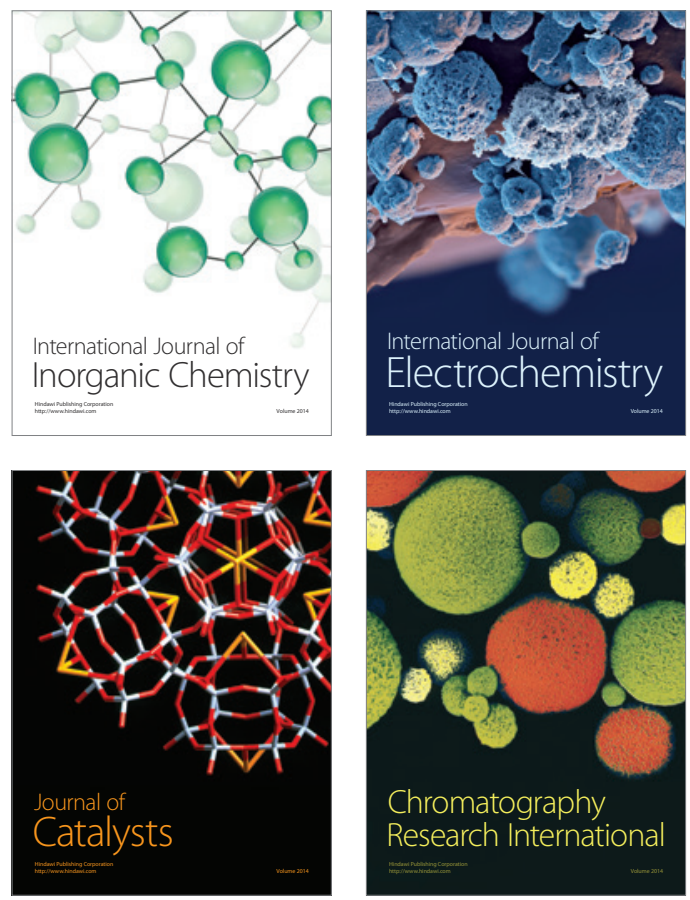
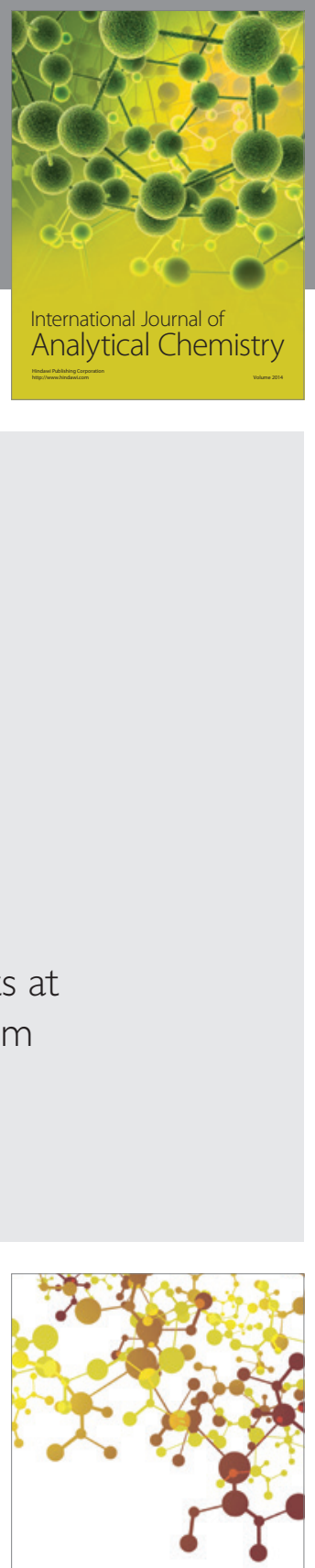

Journal of

Applied Chemistry
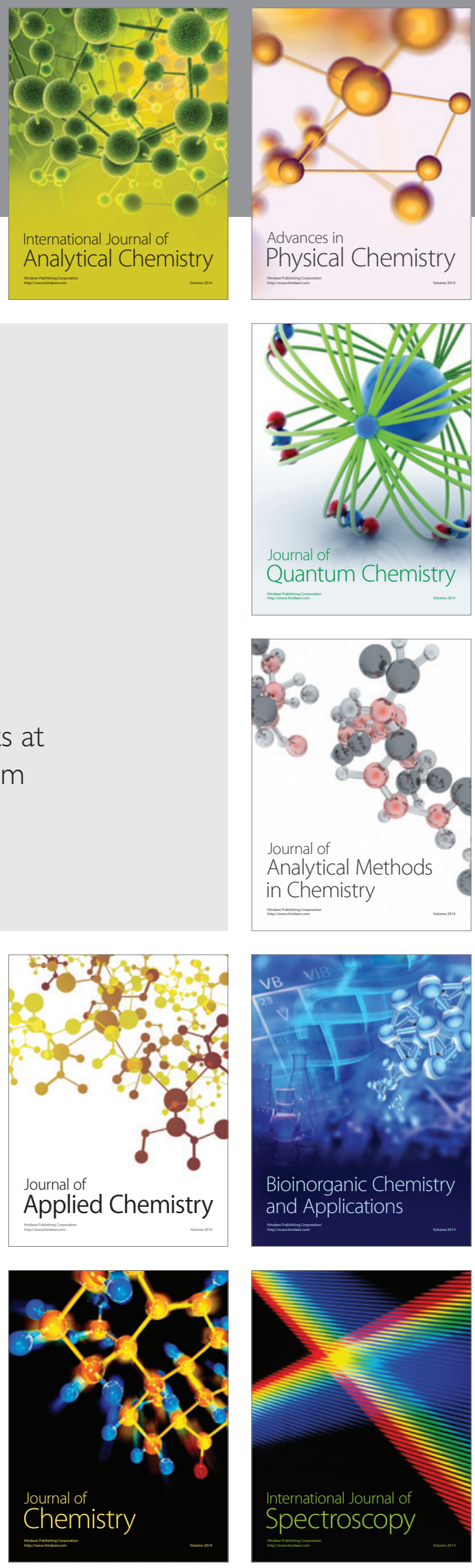